\title{
APLICAÇÃO DE UM MÉTODO PARA CAPACITAÇÃO DE EMPRESAS FORNECEDORAS DA CADEIA AUTOMOTIVA DO RIO GRANDE DO SUL
}

Miguel Afonso Sellitto ${ }^{1}$

Rafael Marquez Gonçalves²

\begin{abstract}
RESUMO
O objetivo deste artigo é apresentar e relatar um caso de aplicação de um método para capacitar fornecedores de cadeias automotivas. O método de pesquisa foi o estudo de caso. As atividades fizeram parte de um Projeto do IELRS (Instituto Euvaldo Lodi RS) cujo objetivo foi aumentar a competitividade de cadeias produtivas pelo desenvolvimento e qualificação de fornecedores. A aplicação envolveu duas empresas sistemistas da cadeia e quinze fornecedoras destas sistemistas, com operações no Rio Grande do Sul. O método é composto por ações de curto prazo, incluindo diagnóstico e plano de trabalho, e ações de longo prazo, incluindo consultoria e capacitação. Os resultados foram medidos por quatro objetivos intermediários (diminuir falhas, aumentar confiabilidade de entrega, implantar ferramentas gerencias, e melhorar qualidade) e dois finais (aumentar volume de negócios e aumentar faturamento). Três dos objetivos intermediários e dois dos finais foram alcançados. O principal resultado do projeto foi o aumento da qualidade de conformação observada nas entregas das fornecedoras.
\end{abstract}

Palavras-chave: Capacitação de fornecedores. Gestão da cadeia de suprimentos. Fornecedores automotivos. Abastecimento industrial.

${ }^{1}$ Doutor, e-mail: sellitto@unisinos.br

2Graduado, e-mail: consultoria@venti.com.br 


\section{INTRODUÇÃO}

O mercado automotivo brasileiro teve avanços significativos, tornando-se em 2010 o quarto maior mercado mundial, com 3,51 milhões de veículos comercializados, o que representou um crescimento de $11,9 \%$ em relação a 2009. A produção avançou para 3,38 milhões de carros, ficando atrás apenas de China, Japão, Estados Unidos, Alemanha e Coréia do Sul. Em síntese, o Brasil é o quarto mercado automotivo, e o sexto na produção automobilística. Este comportamento vem sendo observado desde 2005. A expansão acumulada no período é de $105 \%$ na comercialização e de $43 \%$ na produção de bens automotivos. O Brasil ainda apresenta potencial de crescimento de mercado interno, haja vista sua posição de 6,5 habitantes por veículo, longe dos 1,1 habitante por veículo do Japão, 1,2 habitante por veículo dos Estados Unidos e dos 1,5 de Itália e Canadá. Por mais de 60 anos, a indústria automotiva brasileira tem construído cadeias estruturadas de produção, revigoradas e revitalizadas a partir da década de 1990, com investimentos que superaram os US\$ 50 bilhões entre 1994 e 2010 (ASSOCIAÇÃO NACIONAL DE FABRICANTES DE VEÍCULOS AUTOMOTORES, 2011a; ASSOCIAÇÃO NACIONAL DE FABRICANTES DE VEÍCULOS AUTOMOTORES, 2011b).

O mercado brasileiro automotivo cresceu quase duas vezes mais do que a produção, abastecido por crescentes importações, que chegaram a 660 mil veículos em 2010. Em 2005, os importados representavam 5,1\% do mercado interno; em 2010 atingiram 19\% do total de veículos vendidos. Ao mesmo tempo, as exportações brasileiras de veículos vêm caindo. Em 2005, representaram 31\% da produção, caindo para 15\% em 2010. Importações tornam o mercado mais competitivo, favorecendo o consumidor, mas o que se deixa de produzir internamente reduz o ritmo de investimentos, produção, emprego e consumo gerado pelo pagamento de salários (ASSOCIAÇÃO NACIONAL DE FABRICANTES DE VEÍCULOS AUTOMOTORES, 2011a; ASSOCIAÇÃO NACIONAL DE FABRICANTES DE VEÍCULOS AUTOMOTORES, 2011b). Este descompasso aponta para importante perda de mercado que não pode e não deve ser negligenciada pela indústria.

A indústria automotiva atua em mercado de alta competitividade, no qual, devido aos rigorosos requisitos de negócios, há pouca tolerância a perdas (BORCHARDT et al., 2008). A competitividade na indústria é afetada pelas características de globalização do mercado: a pressão por redução de custos e a manutenção ou elevação dos padrões de qualidade torna-se maior, exigindo das empresas sistemistas e fornecedoras baixos índices de erros de produção e um menor custo total das operações (DIEHL e VACCARO, 2009; FLEURY, WANKE e FIGUEIREDO, 2008).

Scavarda et al. (2001, tradução nossa) relataram pesquisa que identificou alguns dos problemas a serem superados no gerenciamento de cadeias de suprimentos automotivas brasileiras. A FIAT, por exemplo, diminuiu drasticamente o número de fornecedores de primeira camada, desenvolvendo com os mesmos, parcerias estratégicas baseadas em confiança mútua. A General Motors implantou um sistema integrador da cadeia de suprimentos em Gravataí, considerado exemplo mundial da marca. Enquanto que a fábrica de São Caetano do Sul opera com cerca de 400 fornecedores espalhados pelo país, 
a de Gravataí conta com 17 sistemistas responsáveis por certos sub-sistemas e outros 70 fornecedores dentro ou próximos ao complexo. A coleta junto aos fornecedores e o abastecimento de peças na linha de produção são feitas Just-in-Sequence, por um operador logístico. Este modelo já serve de referencial, até para concorrentes, como a Ford que estabeleceu um modelo semelhante na planta de Camaçari (SCAVARDA et al., 2001, tradução nossa).

A competitividade na indústria também é construída pelos fornecedores e se materializa na capacidade de uma cadeia de suprimentos prover valor a seus clientes finais, sobretudo na forma de qualidade de conformação, baixo custo, diferenciação, e serviços de pós-venda (ARRIGONE; ARRIGONE; MUTTI, 2009). Para que se estabeleça uma cadeia sincronizada e ágil, é preciso gerenciar a rede de suprimentos, em relacionamento colaborativo com os fornecedores (BOWERSOX; CLOSS; COOPER, 2006; CHRISTOPHER, 2007). A colaboração não só é necessária, como essencial na cadeia, pois suporta objetivos de custos, qualidade, produtividade e atendimento ao cliente (PEREIRA e FRAZÃO, 2009). Desenvolver um fornecedor pode exigir serviços de consultoria que identifiquem problemas relacionados com a organização e adequação de métodos e processos de fabricação e técnicas gerenciais empregadas no planejamento e controle das atividades industriais. A integração com fornecedores, seguida da incorporação da cultura do cliente pelo fornecedor, pode exigir esforços permanentes de capacitação e apoio à rede fornecedora (KUCHENBECKER, 2006).

O objetivo deste artigo é apresentar e relatar um caso de aplicação de um método para capacitar fornecedores de cadeias automotivas. O método da pesquisa foi o estudo de caso. O método de capacitação foi desenvolvido em conjunto com o Serviço Brasileiro de Apoio às Micro e Pequenas Empresas (SEBRAE), Instituto Gaúcho de Estudos Automotivos (IGEA) e consultoria e foi aplicado a empresas fornecedoras de sistemistas da cadeia automotiva do Rio Grande do Sul. Eventualmente, o fortalecimento da cadeia pode acarretar redução na necessidade de importação de bens automotivos. $O$ restante do artigo traz o referencial teórico sobre gerenciamento de cadeia de suprimentos e aspectos normativos de fornecedores, resultados de pesquisa, discussão e conclusões.

\section{CADEIA DE SUPRIMENTOS E FORNECEDORES NA CADEIA AUTOMOTIVA}

Uma cadeia de suprimentos engloba as empresas que participam das etapas de fornecimento, fabricação, distribuição, venda e pós-venda de um produto ou serviço entregue a um cliente final. As empresas podem ter diversos tamanhos e tipos e desempenhar diversos papéis na cadeia (SCAVARDA e HAMACHER, 2001). O Gerenciamento da Cadeia de Suprimentos (SCM) pode ser descrito como uma evolução da logística empresarial, estendendo-se desde o pedido de matéria-prima do fornecedor até a entrega do produto final ao cliente. Seu objetivo é agregar valor a produtos e serviços e uma de suas abordagens é desenvolver relacionamentos colaborativos com fornecedores (BOWERSOX; CLOSS e COOPER, 2006). As atividades a gerenciar variam de 
acordo com o ramo de atividade e de empresa para empresa, considerando a estrutura organizacional e a importância das operações. A cadeia de suprimentos inclui funções envolvidas no pedido, desenvolvimento de novos produtos, marketing, operações, distribuição, finanças e o serviço de atendimento ao cliente (CHOPRA e MEINDL, 2003). O gerenciamento abrange diversas áreas, tais como previsão de demanda, compras, produção, estoques e transportes, interagindo nas perspectivas estratégicas, táticas e operacionais (CHRISTOPHER, 2007).

Devido à competitividade nas cadeias mundiais, um relacionamento confiável com os fornecedores é relevante. A cadeia automotiva, por exemplo, geralmente é formada por montadoras, sistemistas, fornecedores, varejistas e clientes finais. A tendência é que as montadoras se concentrem nas etapas de concepção do produto, planejamento e montagem final, deixando para outros elos as demais atividades, assumindo um papel mais estratégico do que a simples fabricação. No passado, seu principal objetivo era a redução de custos. Atualmente, a competição também exige diferenciação de produto e aumento de valor agregado ao cliente por serviços associados ao produto (BALLOU, 2006; DAVIS; AQUILANO; CHASE, 2001; PIRES, 2004;).

Nas cadeias de suprimentos, a manufatura pode externalizar atividades de produção, transferindo-as a fornecedores (ANDRADE e FURTADO, 2005). Para tanto, a manufatura deve medir o desempenho dos fornecedores (KRAUSE; PAGELL; CURKOVIC, 2001, tradução nossa). Quando esse não satisfaz, a manufatura pode retomar a produção do item, mudar de fornecedor ou ajudá-lo a melhorar o desempenho (PIRES, 2004). Krause, Scanell e Calantone (2000, tradução nossa) sugerem variar o volume de negócios do fornecedor segundo seu desempenho. Os efeitos da SCM são observados por toda a cadeia: redução de desperdícios na produção; estoques intermediários; tempos de atravessamento; e aumento na capacidade de fornecimento e na flexibilidade da cadeia de suprimentos (LIMA e ZAWISLAK, 2001). É essencial que haja cooperação com os fornecedores, incorporandoos já nas fases iniciais do processo de desenvolvimento do produto e compartilhando riscos, responsabilidades e retribuições (BALDIN; NOVAES; DUTRA, 2003).

A prática da externalização fez surgir uma rede de fornecedores das montadoras automotivas. Uma das principais dificuldades foi garantir a padronização e a qualidade dos fornecimentos (PIRES, 2004). Para tentar solucionar esse problema, foi criada em 1987 a norma ISO série 9000, um certificado de qualidade internacional que busca garantir a padronização da qualidade e nível mundial em vários setores industriais, inclusive o automobilístico. Na indústria automobilística, devido ao alto nível de exigência de algumas peças, as normas da série ISO 9000 tornaram-se insuficientes, pois não chegou a atender algumas exigências do setor, tais como: controle estatístico do processo, custos de fabricação, processo de aprovação de peças de produção, entre outros (HARO e CATEN, 2003).

Para suprir tais carências, normas específicas surgiram, tais como: a QS-9000, nas montadoras americanas Crysler, Ford e General Motors; a VDA 6, das alemãs: Volkswagen, Audi e Mercedes-Benz; EAQF, das francesas: Renault, Peugeot e Citroen e AVSQ, da 
italiana Fiat. Esta diversidade trouxe dificuldades, pois fornecedores foram obrigados a atender simultaneamente requisitos de várias normas para operar com mais de uma montadora. Tentando retomar a padronização, foi criada a TS-16949 (GUARNIERI e HATAKEYAMA, 2005), destinada aos fornecedores de montadoras, mas também aplicada em toda a cadeia de suprimentos do setor automotivo (HARO e CATEN, 2003).

Os fatores que influenciam no desenvolvimento de fornecedores extrapolam a norma. Com base em pesquisa realizada com 110 fornecedores de um sistemista da indústria americana, Johnson (2002, tradução nossa) relata que a simples adoção dos elementos da norma não constitui garantia de resultado, pois as aplicações eram demasiadamente focada no sistema e não nos resultados do sistema. Furlan, Grandinetti e Camuffo (2007, tradução nossa) apresentam pesquisa com 472 empresas e estudo de caso realizado na Itália com 10 empresas. Os autores identificam, entre outros, a presença de gestão cooperativa dos fornecimentos e de codificação do conhecimento como pré-requisitos para o desenvolvimento de fornecedor, independente de normalização.

O relacionamento entre sistemistas e fornecedores no Brasil depende de associações de classe da indústria (DIEHL e VACCARO, 2009). Mesquita, Lazzarini e Cronin (2008, tradução nossa) realizaram pesquisa com 182 empresas da indústria de autopeças brasileira, objetivando identificar fatores de competitividade. Os autores identificaram que a combinação de esforços de relacionamento entre elos da cadeia e o suporte de instituições de classe e governamentais são fundamentais para o desempenho da cadeia. Em particular, o suporte institucional dá condições de desenvolvimento de relações de benefícios mútuos entre empresas fornecedoras e clientes.

\section{A PESQUISA: METODOLOGIA}

O método de pesquisa foi o estudo de caso. Foi aplicado um método criado pela empresa Venti Inteligência em Projetos, dentro do Projeto de Desenvolvimento e Qualificação de Fornecedores da Cadeia Automotiva do Rio Grande do Sul do Instituto Euvaldo Lodi em parceria com o SEBRAE Nacional e apoio do IGEA. O método considera o efeito sinérgico que relações diádicas podem trazer no resultado das empresas. O projeto durou quinze meses, entre 2010 e 2011. Contou primeiramente com uma articulação política a fim de sensibilizar sistemistas da cadeia automotiva do Rio Grande do Sul para serem âncoras do projeto e assim indicar suas fornecedoras para receber o método de capacitação. Foram escolhidas empresas de micro e pequeno porte segundo: características do produto/ serviço; qualidade dos processos internos do fornecedor; e potencial de contribuição à estratégia da empresa âncora. Duas sistemistas, A e B, indicaram respectivamente sete e oito fornecedores para participar do projeto. A está localizada em Gravataí e é líder de tecnologias para eixos diferenciais, cardans, suspensão e de componentes de reposição originais. A base de clientes inclui todos os maiores fabricantes automotivos, de veículos comerciais e fora-de-estrada. Tem como certificações ISO 9000; ISO TS 16949 e ISO 14001. B é sediada em Porto Alegre e é a maior fabricante especialista em sistemas de 
direção da América Latina e projeta, desenvolve, comercializa, produz e prestar serviço pós-venda a sistemas de direção para aplicação em veículos automotores e aplicações náuticas. Também está certificada com ISO 9001; ISO TS 16949 e ISO 14001.

A Figura 1 sintetiza a nomenclatura: sistemistas que fornecem diretamente para as montadoras (Camada 1), e fornecedores dos sistemistas (Camada 2).

Figura 1: Nomenclatura utilizada no artigo

Camada 1
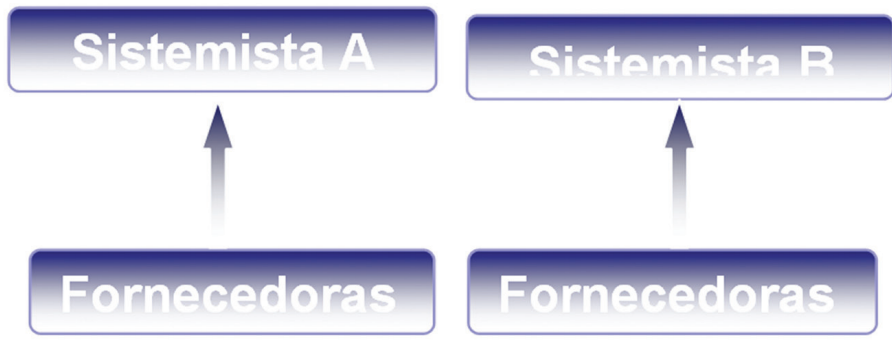

Fonte: Dos autores (2011)

As fornecedoras são: uma de Porto Alegre; três da região da serra gaúcha; e onze da Grande Porto Alegre, totalizando quinze empresas. As categorias de fornecimento são: uma de injetado plástico; duas de peças de borracha, duas de peças metálicas; duas de estampados; duas de tratamentos superficiais; e seis de serviços de usinagem. 0 método inclui duas etapas: ações de curto prazo (seis meses), que geraram plano de trabalho baseado em diagnósticos e análises de causas raízes; e ações de médio e de longo prazo (um ano e dois anos) baseadas em capacitações customizadas e consultorias de sustentação de conhecimento.

\subsection{Ações de curto prazo: diagnóstico}

As ações de curto prazo aprimoraram a relação entre sistemistas e fornecedoras, e seguiram as etapas expostas na Figura 2. 
Figura 2: Etapas das Ações de Curto Prazo

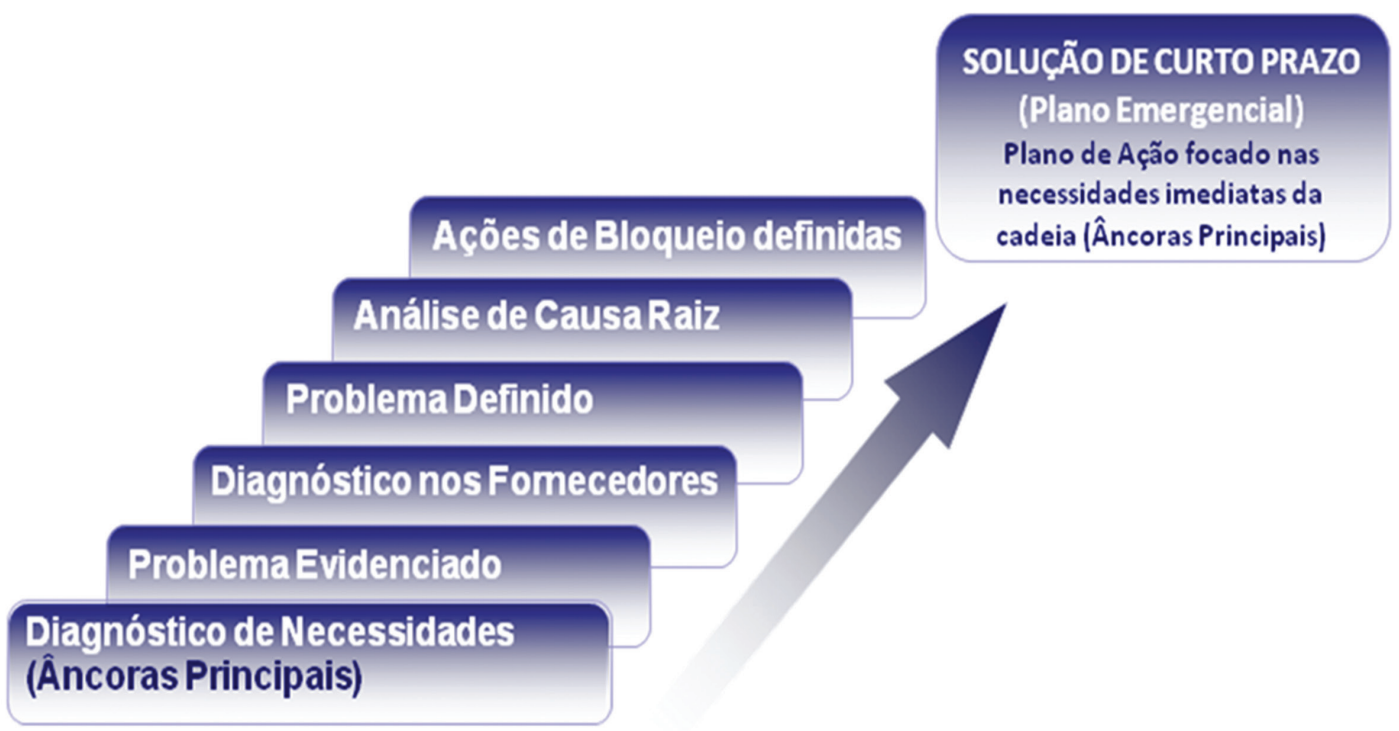

Fonte: Dos autores (2011)

Em reunião mediada pela Venti com as sistemistas, foram apresentados os objetivos do projeto e os resultados esperados, evidenciados os principais problemas e as características dos fornecedores participantes do projeto. Foram apresentados indicadores mensurados para as fornecedoras, que consideram desempenho em qualidade, comercial, logística, e engenharia. Resultou um perfil expondo qualidade e fraquezas da cadeia de suprimentos. As análises orientaram os diagnósticos de campo realizados nas quinze fornecedoras entre junho e setembro de 2010. As necessidades levantadas nas reuniões com as sistemistas, também serviram de base para definir o programa, a carga horária e os temas das capacitações: Qualidade, Gestão Estratégica, Indicadores, Gestão de Projetos e Manufatura Enxuta. Também foi apresentado o método de capacitação, para criar comprometimento e salientar a importância da aprendizagem conjunta.

Após esta etapa, a Venti realizou uma coleta de dados própria nas quinze fornecedoras, a fim de confrontar com as informações relatadas pelos sistemistas. A Venti consultou de forma independente os sistemas de informação das empresas. Nesta análise foram levantados dados como: produtos e serviços entregues às âncoras do projeto; critérios de aceitação do produto; indicadores não atendidos; problemas evidenciados; pontos de melhoria no compartilhamento de informações; existência de contramedidas na ocorrência de problemas; e mecanismos de aprendizagem e compartilhamento do que foi aprendido. Os casos relatados nos sistemas de informação das empresas serviram como fonte para definir e classificar em categorias os problemas que seriam tratados no projeto, conforme a Tabela 1. A tabela também traz o percentual de empresas que apresentaram cada categoria de problema ao menos uma vez nos últimos seis meses. 
Tabela 1: Categorias de problemas em relação ao total diagnosticados

\begin{tabular}{|l|l|l}
\hline Tipo de problema & $\begin{array}{l}\% \text { de } \\
\text { problemas } \\
\text { em cada } \\
\text { categoria }\end{array}$ & $\begin{array}{l}\text { \% de } \\
\text { empresas que } \\
\text { apresentaram } \\
\text { o problema }\end{array}$ \\
\hline Gestão & $9 \%$ & $33 \%$ \\
\hline Especificação técnica & $15 \%$ & $53 \%$ \\
\hline Comercial & $23 \%$ & $80 \%$ \\
\hline Qualidade & $6 \%$ & $20 \%$ \\
\hline Comunicação & $23 \%$ & $80 \%$ \\
\hline PPAP & $4 \%$ & $13 \%$ \\
\hline Prazo de atendimento & $15 \%$ & $53 \%$ \\
\hline Pesquisa e desenvolvimento de produtos & $3 \%$ & $13 \%$ \\
\hline Capacitação técnica e gerencial & $2 \%$ & $7 \%$ \\
\hline
\end{tabular}

Fonte: Dos autores (2011)

Em reuniões com gestores das empresas, evidenciou-se que a comunicação inadequada entre sistemista e fornecedor estava ligada a problemas comerciais, de especificações técnicas e atendimento a prazos. Ou seja, a comunicação inadequada causava $76 \%$ dos problemas diagnosticados que geravam ineficiências na cadeia. Em síntese, para esta cadeia, os problemas se concentram mais nas conexões do que nos processos internos das empresas. Problemas relacionados à comunicação ineficaz e relacionamento comercial foram observados em $80 \%$ das empresas. Tais dados demonstram que há necessidade de melhoria também por parte das sistemistas, não somente dos fornecedores, visto que, o compartilhamento de informações depende muito mais da sistemista do que da fornecedora. Problemas ligados a especificações técnicas e atendimento aos prazos foram observados em $53 \%$ das empresas. Em atendimento a prazos, foram observados problemas ligados à insegurança na programação da sistemista e pouco tempo para a entrega de orçamentos de grandes volumes. Ficou evidente a necessidade de formalizar regras de especificações técnicas ligadas à qualidade e as rotinas entre áreas em comum, como comercial e compras. Por fim, observou-se que $24 \%$ das fornecedoras apresentaram problemas internos como: gestão, qualidade, PPAP, capacitação e pesquisa e desenvolvimento. Estes itens foram atendidos nas ações de longo prazo, que incluíram treinamentos e consultorias específicas. 


\subsection{Ações de curto prazo: plano de trabalho}

Para a solução dos problemas diagnosticados, foram criados planos de trabalho específicos para cada fornecedor e sistemista. A fim de encontrar a causa raiz dos problemas, foi utilizada a análise dos "cinco porquês". Foram identificadas as motivações dos problemas, propostas ações de bloqueio, definição dos meios, responsáveis e prazos para as ações. As reuniões para a criação dos planos de trabalho foram mediadas pela Venti e realizadas nas plantas dos fornecedores. Participaram os responsáveis pela qualidade, comercial, logística e engenharia e os engenheiros da qualidade das sistemistas. Concluiu-se que o foco deveria ser melhorar a comunicação entre sistemista e fornecedor, dando dinamismo e fluidez aos processos que envolvem o fornecimento.

Resultados imediatos importantes foram atingidos nas ações de curto prazo. Foram resolvidos problemas de logística (peças estocadas), comerciais (preços), de engenharia (desenvolvimentos de produtos e ferramental), de qualidade (relatórios de não conformidades (RNC's)) e gestão (por meio de PCP - Planos de Curto Prazo). Os planos de curto prazo resolveram muitos dos problemas levantados nos diagnósticos e nas reuniões de validação das ações e trouxeram benefícios concretos e imediatos para a cadeia, com reflexo financeiro direto, tanto para fornecedoras como para as sistemistas.

Os resultados estão apresentados no Quadro 1.

Quadro 1: Benefícios apurados nos planos de curto prazo

\begin{tabular}{|c|c|c|}
\hline Empresa & Pendência & Resultado \\
\hline Empresa 1 & $\begin{array}{l}550 \text { peças estocadas para } \\
\text { reaproveitamento sem definição } \\
\text { há mais de } 1 \text { ano } \\
\text { - Estoque } 289 \text { kg de alumínio } \\
\text { especial, sem definição de } \\
\text { destino. }\end{array}$ & $\begin{array}{l}\text { - } 550 \text { peças colocadas em linha de } \\
\text { produção } \\
\text { - } 289 \mathrm{~kg} \text { de alumínio em } \\
\text { processo de repasse para outro } \\
\text { fornecedor }\end{array}$ \\
\hline Empresa 2 & $\begin{array}{l}\text { - Processo de desenvolvimento do } \\
\text { ferramental } 1533011 \text { parado. } \\
\text { - Processo de desenvolvimento do } \\
\text { novo projeto VIVA RHD } 6100107 \\
\text { parado } \\
\text { Falta de consistência nas } \\
\text { programações do PCP da } \\
\text { sistemista }\end{array}$ & $\begin{array}{l}\text { - Processo retomado. Ferramental } \\
\text { em fase de conclusão. } \\
\text { - } \quad \text { Processo retomado. Ferramental } \\
\text { esta em fase de conclusão. } \\
\text { - Novo processo de PCP foi } \\
\text { desenhado junto com a âncora }\end{array}$ \\
\hline
\end{tabular}




\begin{tabular}{|c|c|c|}
\hline Empresa 3 & $\begin{array}{l}\text { - } 4.000 \text { peças estocadas há mais } \\
\text { de } 1 \text { ano sem definição } \\
\text { - } \text { Processo de compra de } \\
\text { reservatório parado, } \\
\text { investimento alto sem definição } \\
\text { de aprovação. }\end{array}$ & $\begin{array}{l}\text { - } 4.000 \text { peças já aproveitadas na } \\
\text { linha de montagem. } \\
\text { - } \quad \text { Reservatório qualificado, lote de } \\
\text { teste produzido e em teste. }\end{array}$ \\
\hline Empresa 4 & $\begin{array}{l}\text { - } 12.000 \text { peças sem definição de } \\
\text { estar ou não conforme há mais } \\
\text { de oito meses } \\
\text { - } \quad \text { Programação chega com prazo } \\
\text { muito curto de produção }\end{array}$ & $\begin{array}{l}\text { - } 12.000 \text { peças aprovadas na linha } \\
\text { de montagem } \\
\text { - } \quad \text { Estabelecimento de nova } \\
\text { rotina de programação com a } \\
\text { participação do EQF. }\end{array}$ \\
\hline Empresa 5 & $\begin{array}{l}\text { - Horizonte de programação de } \\
\text { produção curto, dificulta boa } \\
\text { compra de material } \\
\text { - Especificações de matéria prima } \\
\text { sem alternativas nacionais. }\end{array}$ & $\begin{array}{l}\text { - Compra mais econômica de } \\
\text { materiais } \\
\text { - Estudo de alternativas de } \\
\text { matéria prima nacional para } \\
\text { redução de custos. }\end{array}$ \\
\hline Empresa 6 & $\begin{array}{l}\text { Dimensão correta de um furo da } \\
\text { peça C22661, U221369 (grande } \\
\text { volume de produção) }\end{array}$ & $\begin{array}{l}\text { - Definição da dimensão e } \\
\text { eliminação do risco de rejeição }\end{array}$ \\
\hline Empresa 7 & $\begin{array}{l}\text { Preços defasados (sem reajuste } \\
\text { há mais de } 2 \text { anos) na maioria } \\
\text { dos produtos. }\end{array}$ & $\begin{array}{l}\text { - Preços reajustados para a } \\
\text { maioria dos produtos defasados. }\end{array}$ \\
\hline Empresa 8 & $\begin{array}{l}\text { Estavam abertas } 98 \text { RNCs } \\
\text { de qualidade do produto } \\
\text { aguardando definição conjunta. }\end{array}$ & $\begin{array}{l}\text { - Todas as } 98 \text { RNCs foram } \\
\text { resolvidas. }\end{array}$ \\
\hline
\end{tabular}

Fonte: Dos autores (2011)

\subsection{Ações de médio e longo prazo: capacitações e consultorias}

O passo seguinte foram capacitações técnicas e organizacionais. Foram realizadas cinco atividades customizadas para atender as demandas levantadas nos diagnósticos. Como exemplo de customização, estava prevista no planejamento inicial do projeto uma capacitação em qualidade. No entanto, os diagnósticos revelaram a necessidade de aprofundar alguns assuntos e foram realizadas três capacitações: Metodologia de Análise e Solução de Problemas (MASP); Processo de Aprovação de Peças de Produção (PPAP) Básico; e PPAP Avançado. 
Fornecedores da indústria automotiva, usualmente, estão certificados pela ISO 9001, ISO TS16949 e possuem PPAP desenvolvido e aprovado pelo comprador. No entanto, os diagnósticos revelaram que os fornecedores completam suas cargas de trabalho com fornecimentos fora da cadeia automotiva, para clientes que não têm o mesmo nível de exigência. Também revelaram que os serviços e produtos da cadeia têm se comportado como commodities em termos de preço, com margens pequenas. Como a competitividade é construída pela gestão inteligente dos custos de produção e a qualidade é rigorosamente controlada por processos gerenciais articulados, processos avançados de produção aliados a processos avançados de Garantia de Qualidade são essenciais na indústria. Os fatores que influenciam os padrões de qualidade na indústria automotiva são complexos e exigem atualização constante por parte das empresas fornecedoras. Sendo assim, além dos três módulos originais de capacitação em qualidade, também foram realizados mais dois módulos: gestão estratégica, indicadores e gestão de projetos; e Manufatura Enxuta.

Ao total, foram oitenta horas de treinamento, ministrados por profissionais do mercado, com mestrado em engenharia de produção e experiência no mercado automotivo brasileiro e internacional. Os treinamentos foram disponibilizados a dois colaboradores por empresa fornecedora. A meta de participação das empresas participantes no projeto era de $75 \%$. A justificativa para uma não adesão total (100\%) é a de que os treinamentos foram realizados em Porto Alegre, durante a semana em horário comercial e muitas empresas eram da região metropolitana e região da serra do Rio Grande do Sul, o que, de certa forma, demandava perda de um dia inteiro de trabalho na empresa fornecedora participante. Ainda assim, a adesão média foi acima do esperado: foram capacitados trinta e dois profissionais, a maioria nos três módulos.

\subsection{Ações de médio e longo prazo: consultorias}

Os diagnósticos, além de definir e customizar o conteúdo das capacitações, direcionaram as ações de consultoria. Além das consultorias do início do projeto, que geraram os planos de ação de curto prazo, após cada capacitação, foram realizadas as consultorias de intervenção, que focaram na sustentação dos conhecimentos trabalhados nas capacitações e na realização de ações específicas em campo. O resultado destas consultorias foi a construção de um plano de ações de médio e prazo focado na matéria da capacitação. Após cada tema de capacitação, foram disponibilizadas oito horas de consultoria para cada empresa fornecedora. Estas consultorias visavam a observar o entendimento dos conteúdos das capacitações e orientar a aplicação dos principais conceitos. As consultorias tiveram suas entregas finais específicas, visto os diferentes níveis de necessidades das quinze empresas. Optou-se por entregar planilhas e documentos que pudessem servir de guia e estímulo para continuidade dos trabalhos a médio e longo prazo.

Inicia-se pelas consultorias em qualidade: MASP, PPAPI, PPAP II. Após o treinamento, o consultor visitou as empresas fornecedoras a fim de presenciar o entendimento e a 
aplicação dos conhecimentos adquiridos no treinamento. Para uma identificação do estado atual, foi realizada uma auditoria preliminar focada em cinco ações: identificação das não-conformidades; priorização das não-conformidades; análise de causa-raiz; ações de bloqueio de causa-raiz e gestão do sistema de garantia da qualidade. Para todos os itens, foram descritas as posições e seus respectivos estados atuais em percentuais. Para os itens com lacunas, foram identificadas as falhas, as ações de bloqueio, os responsáveis e os prazos.

As consultorias em gestão estratégica, indicadores e gestão de projetos ocorreram também após o módulo de gestão estratégica e gestão por indicadores. O consultor visitou as empresas fornecedoras e auxiliou no planejamento estratégico ou na melhora do planejamento existente. O modelo se baseava na construção de missão e objetivos estratégicos. Resultados, clientes, processos internos e aprendizagem desenvolvida tiveram metas definidas e indicadores para medi-las. Foi desenvolvida uma fórmula para o cálculo e um responsável pelo indicador. Caso a meta não fosse atingida, uma ação deveria ser ativada pelo responsável com a definição de um custo adicional e um prazo para atingir o objetivo.

Por fim, aborda-se a consultoria sobre manufatura enxuta e suas principais ferramentas. As montadoras automotivas têm se utilizado dos sistemas de produção puxada e ágil, conceitos derivados do sistema Toyota de Produção, o que motivou o módulo. Estes conceitos e ferramentas têm contribuído consideravelmente para a eliminação de desperdícios e a melhoria contínua dos processos e produtos, objetivando responder de forma satisfatória às necessidades do mercado automotivo. Sendo assim, é necessário que toda a cadeia de suprimentos se adeque às normas de qualidade existentes no mercado, visando uma maior integração entre os sistemistas, fornecedores e subfornecedores, para assim otimizar tempo e recursos, o que automaticamente maximiza a lucratividade de toda a cadeia.

\section{RESULTADOS}

O primeiro resultado de pesquisa foi a identificação do perfil de problemas desta amostra representante da cadeia automotiva do Rio Grande do Sul, evidenciados nos diagnósticos realizados nos fornecedores e nas duas sistemistas. Este prévio diagnóstico foi fundamental para orientar as capacitações e os trabalhos das consultorias de intervenção, de forma padronizada em cada empresa fornecedora (Gráfico 1). Os problemas internos das empresas representam $24 \%$ da amostragem, contudo os problemas decorrentes da interrupção na comunicação representam $76 \%$ dos problemas evidenciados.

Por vezes, a sistemista não compreende profundamente seus fornecedores e suas demandas, havendo assim a necessidade de uma aproximação maior entre sistemista e fornecedor. Então, o ideal seria uma visita regular de engenheiros de qualidade (EQF's) nas empresas fornecedoras para observar processos e estruturas fabris e realizar 
trabalhos de melhoria em conjunto. Ações deste tipo gerarão estruturas de participação, desenvolvendo as conexões uniformes entre os processos das sistemistas e os processos das fornecedoras, alcançando a esperada confiança mútua no relacionamento.

\subsection{Indicadores do método}

O método utilizado no projeto foi concebido com o objetivo de ampliar os negócios e a lucratividade entre sistemistas e fornecedoras, por meio de um conjunto de ações voltadas à qualificação das empresas para o atendimento dos requisitos préestabelecidos e exigidos pelas sistemistas. Os objetivos esperados foram divididos em: resultados intermediários e resultados finalísticos.

Para a mensuração dos ganhos do projeto, indicadores de desempenho foram definidos na reunião inicial entre a consultoria e os sistemistas. Foram coletados dados antes das atividades, em abril de 2010; durante, em novembro de 2010; e depois de finalizadas as atividades, em maio e junho de 2011. Para os resultados intermediários, foram considerados quatro objetivos estratégicos e quatro indicadores. Todos os dados foram coletados nas bases de dados das empresas e compilados pela consultoria. Não foi objetivo de projeto mensurar os indicadores do ponto de vista financeiro. A evolução de resultados é apresentada no Quadro 2.

Quadro 2: Resultados Intermediários

\begin{tabular}{|c|c|c|}
\hline Objetivo & Indicador & Situação \\
\hline $\begin{array}{l}\text { Diminuir o Índice de } \\
\text { falhas na entrega dos } \\
\text { produtos }\end{array}$ & $\begin{array}{l}\text { PPM - Partes por } \\
\text { milhão de falhas }\end{array}$ & $\begin{array}{l}10 \text { fornecedoras chegaram a zero PPM } \\
2 \text { fornecedoras mantiveram zero PPM; } \\
1 \text { diminuiu seu PPM sem chegar a zero; } \\
2 \text { aumentaram seu PPM. }\end{array}$ \\
\hline $\begin{array}{l}\text { Aumentar cumprimento } \\
\text { do prazo e quantidade } \\
\text { de entrega }\end{array}$ & $\begin{array}{l}\text { IEE - Índice de } \\
\text { eficiência de entrega }\end{array}$ & $\begin{array}{l}11 \text { empresas mantiveram IEE = } 100 \% \text {; } \\
2 \text { se aproximaram de } 100 \% \text {; } \\
2 \text { baixaram seu IEE. }\end{array}$ \\
\hline $\begin{array}{l}\text { Implantar ferramentas } \\
\text { gerenciais }\end{array}$ & $\begin{array}{l}\% \text { empresas com } \\
\text { ferramental implantado }\end{array}$ & $\begin{array}{l}\text { Todas as empresas implantaram } \\
\text { ferramentas gerenciais }\end{array}$ \\
\hline $\begin{array}{l}\text { Melhorar a qualidade } \\
\text { dos produtos }\end{array}$ & $\begin{array}{l}\% \text { de fornecimentos } \\
\text { aceitos }\end{array}$ & $\begin{array}{l}11 \text { empresas aumentaram seus \% de } \\
\text { entregas aceitas; } \\
2 \text { mantiveram seu \% em } 100 \% \text {; } \\
2 \text { diminuíram seu \%. }\end{array}$ \\
\hline
\end{tabular}


No índice de falhas na entrega dos produtos (tipo de produto, embalagem, local de entrega, documentação), doze empresas atingiram zero PPM. Destas, duas já apresentavam este resultado na primeira medição, mas dez atingiram-no apenas na terceira, o que indica que as atividades do projeto foram contributivas. Duas fornecedoras aumentaram seu PPM na terceira medição, em relação à primeira, o que não pode ser explicado pelos executores do projeto. Finalmente, uma fornecedora diminuiu seu PPM, sem chegar a zero. Foi observada evolução, pois passou-se de 447 PPM para 48 PPM.

No cumprimento de prazos e quantidades (IEE), foi observado que onze fornecedoras mantiveram-no em $100 \%$ ao longo do tempo do projeto. Duas fornecedoras conseguiram evoluir seu patamar de entrega no prazo e se aproximaram de $100 \%$ de IEE. Duas empresas baixaram seus índices. Devido aos altos volumes de fornecimento, em muitos casos, as empresas da cadeia têm maiores dificuldades em atender em 100\% o IEE. Quanto a ferramentas gerenciais, $100 \%$ das empresas implementaram ao menos uma ferramenta gerencial durante o projeto. Quanto ao percentual de produtos aceitos por qualidade, duas fornecedoras mantiveram seus índices em $100 \%$. Treze fornecedoras aumentaram seus percentuais de produtos aceitos em inspeções de qualidade. Este talvez tenha sido o mais expressivo dos resultados obtidos pelo projeto.

Os indicadores de resultados intermediários do projeto se mostraram positivos em três dos quatro indicadores mensurados. Apenas na eficiência de entrega é que parece não ter havido ganho efetivo global, pois duas fornecedoras subiram sua eficiência, mas duas caíram. Ações posteriores devem ser programadas para que se entenda o motivo desta frustração.

Passa-se aos resultados finais. Os objetivos estratégicos mensurados foram: aumentar o volume de negócios gerados entre âncora e fornecedor; e aumentar o percentual de faturamento das empresas em $10 \%$. Os indicadores mensurados foram: quantidade de itens fornecidos; faturamento bruto para as âncoras; e faturamento bruto global. Os resultados são apresentados no Quadro 3.

Quadro 3: Resultados finais

\begin{tabular}{|l|l|l|}
\hline \multicolumn{1}{|c|}{ Objetivo } & \multicolumn{1}{c|}{ Indicador } & \multicolumn{1}{c|}{ Situação } \\
Aumentar o volume de negócios & Quantidade de itens & Aumento de 14\% ao \\
gerados entre âncora e fornecedor & longo do projeto. \\
& $\begin{array}{l}\text { Faturamento bruto } \\
\text { para as sistemistas }\end{array}$ & $\begin{array}{l}\text { Aumento de 9,2\% ao } \\
\text { longo do projeto. }\end{array}$ \\
Aumentar o percentual de & Faturamento bruto & Aumento de 2,7\% ao \\
faturamento das empresas em 10\% & global & longo do projeto. \\
\hline
\end{tabular}

Fonte: Dos autores (2011) 
Em relação ao aumento do volume de negócios gerados, observou-se um aumento de $14 \%$ na quantidade de itens fornecidos às sistemistas. O volume de vendas das sistemistas cresceu $7,8 \%$ no período, o que indica que aumentou a fatia de compras reservada às empresas que participaram do projeto. Houve aumento de $9,2 \%$ do faturamento bruto das fornecedoras para as sistemistas. O objetivo estratégico de aumentar o faturamento em $10 \%$ não foi alcançado. Em análise entre a Venti a as sistemistas, concluiu-se que o objetivo também depende de outras variáveis do mercado automobilístico, fora do controle dos atores do projeto. Portanto, concluiu-se que houve problema na formulação; mesmo que o faturamento houvesse crescido $10 \%$, não se teria certeza se o foi por causas externas, tais como oscilações naturais de mercado, ou pelas ações de treinamento e consultoria.

Os gráficos 1, 2 e 3 demonstram a evolução dos indicadores durante e após a aplicação do método. Observa-se, no Gráfico 1, um aumento na quantidade total de peças fornecidas em $14 \%$ ao longo do projeto, mais do que o crescimento de vendas das sistemistas. Isto representa um aumento significativo do volume de negócios da cadeia estudada. No Gráfico 2, observa-se que em abril/2010 e nov-dez/2010 o faturamento bruto para as sistemistas manteve-se aproximadamente constante. Entretanto, houve queda da produção nos meses de novembro e dezembro e conseqüentemente queda na compra de produtos e serviços dos fornecedores. Isto leva a concluir que o negócio melhorou no segundo semestre de 2010, pois a queda mostrada no Gráfico 3 não foi sentida pelos fornecedores.

Gráfico 1: Quantidade de itens fornecidos às sistemistas

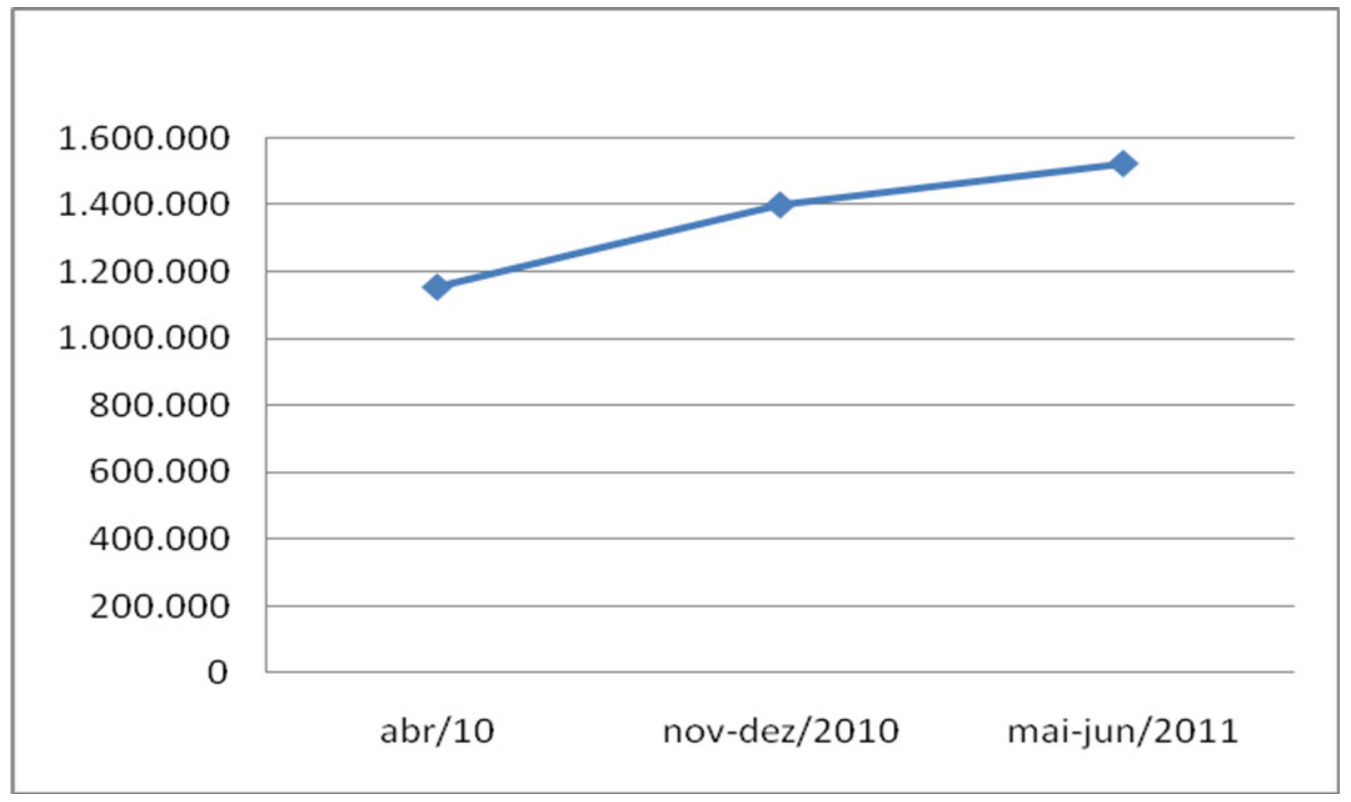

Fonte: Dos autores (2011) 
Gráfico 2: Faturamento bruto dos fornecedores das sistemistas

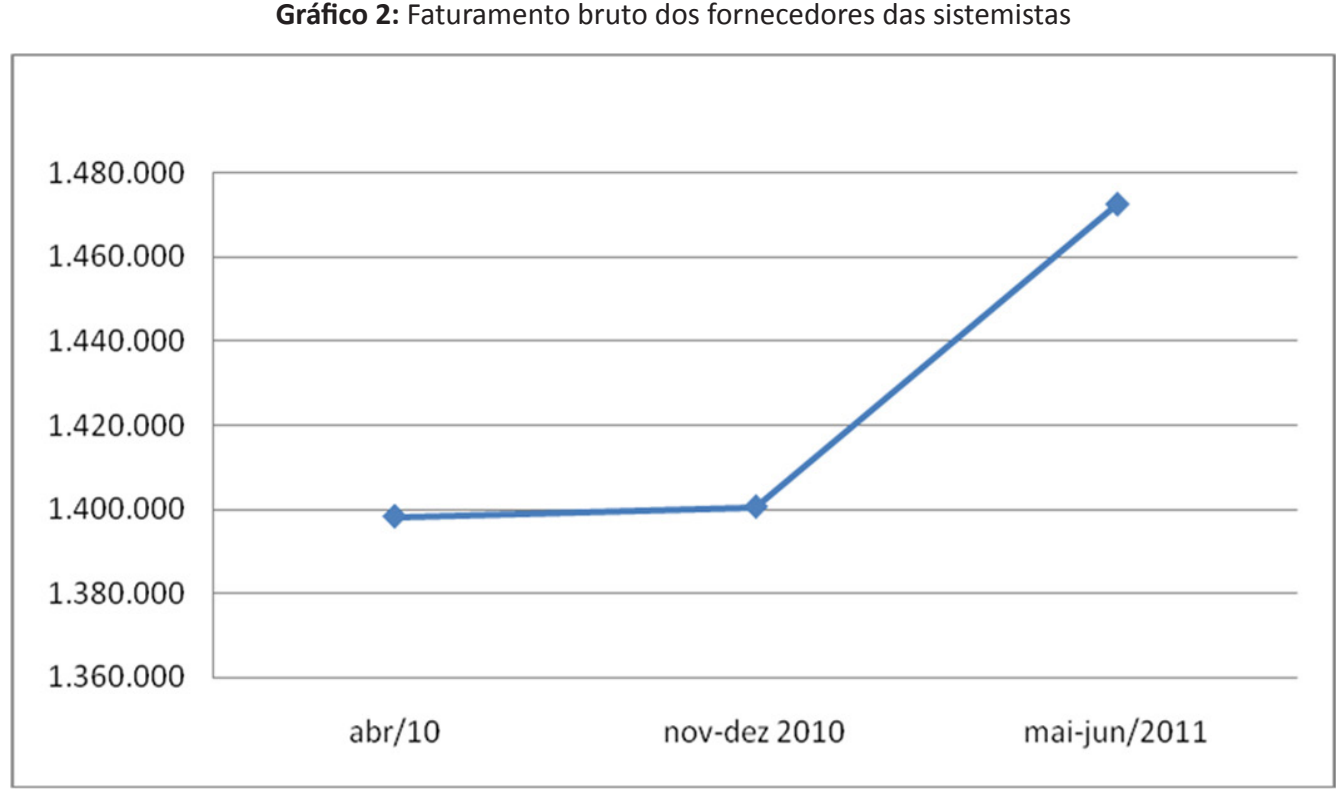

Fonte: Dos autores (2011)

Gráfico 3: Faturamento

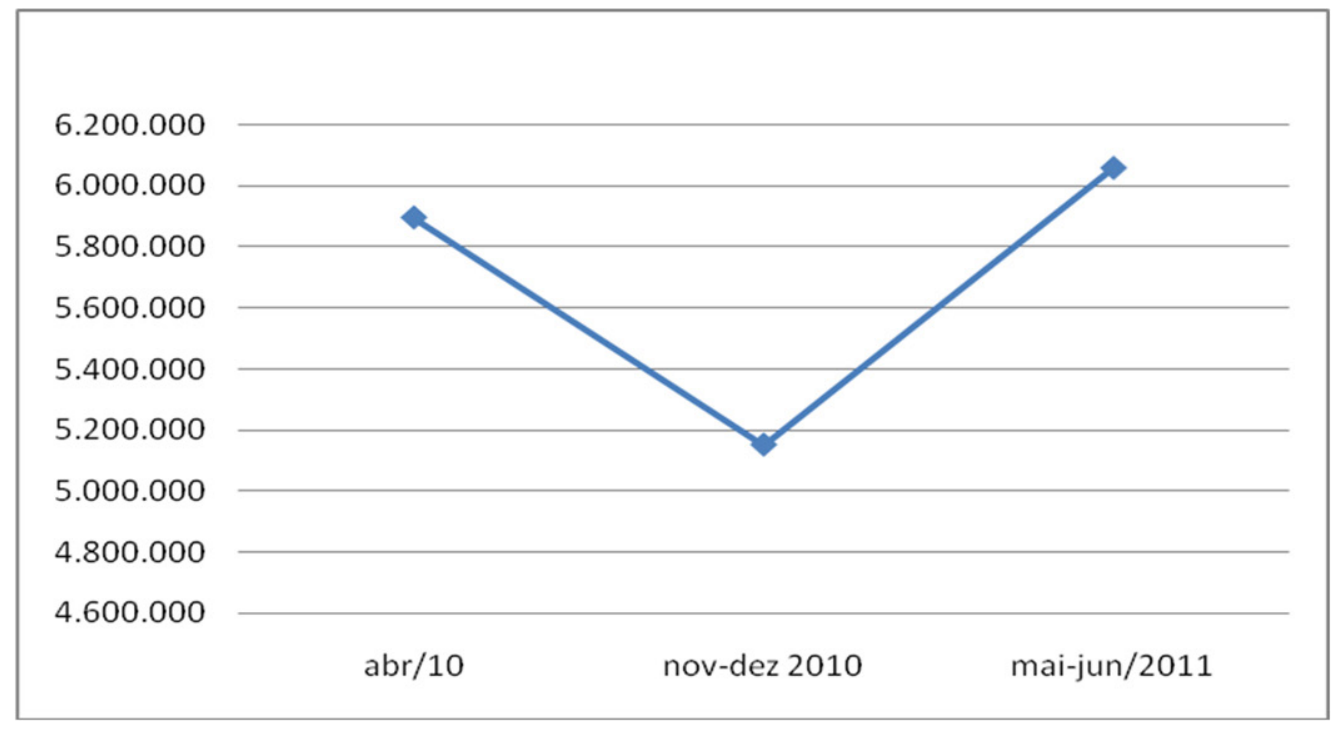

Fonte: Dos autores (2011) 
Observa-se no Gráfico 3 o comportamento do faturamento bruto total das empresas no período. Houve um aumento de $2,7 \%$ do faturamento bruto total de mai-jun/2011 em relação a abril/2010. O faturamento das sistemistas representa aproximadamente $25,2 \%$ do faturamento bruto total. Um aumento de 9,2\% nos negócios com as sistemistas representa aproximadamente $2,3 \%$ sobre o total. Isto indica que o aumento do faturamento bruto total foi alavancado pela influência da melhoria dos negócios com as duas sistemistas.

Espera-se que tais indicadores melhorem ao longo do tempo, visto que há ações ainda não concluídas nos planos de longo prazo, formuladas e iniciadas após as capacitações nas empresas. Com a implementação das ferramentas e metodologias fornecidas nas capacitações e consultorias, espera-se um novo salto na qualidade e no faturamento das empresas participantes do projeto. Não foi objetivo de projeto criar mecanismos sob a ótica de sustentabilidade do gerenciamento do modelo da cadeia de suprimentos, pois a complexidade inerente ao modelo está acima dos objetivos iniciais.

\section{CONSIDERAÇÕES FINAIS}

O objetivo deste artigo foi apresentar e relatar um caso de aplicação de um método para capacitar fornecedores de cadeias automotivas. Participaram quinze empresas fornecedoras de peças e serviços e duas sistemistas da cadeia automotiva.

O método aplicado foi dividido em duas etapas: ações de curto prazo, compostas por diagnósticos e planos de ação de curto prazo; e ações de longo prazo, compostas por capacitações e consultorias. No diagnóstico, foram observados, relatados e classificados problemas encontrados nas empresas fornecedoras. Os problemas com maior incidência foram comerciais e de comunicação, observados em $80 \%$ das quinze empresas estudadas. Durante a execução dos planos de curto prazo, foram resolvidos muitos dos problemas levantados nos diagnósticos, o que trouxe benefícios concretos e imediatos para a cadeia, com reflexo financeiro direto. Dos quatro objetivos estratégicos impostos para esta etapa, três foram bem sucedidos e um não trouxe resultado nem positivo nem negativo. A avaliação final do projeto mensurou o impacto das ações em três objetivos de longo prazo. Um deles mostrou-se mal formulado, pois também dependia de outras variáveis de mercado, fora do alcance das ações de projeto. Os outros dois objetivos finais foram alcançados.

Espera-se que, com a continuidade das ações, outros benefícios surjam para a cadeia e para as empresas, visto que muitos dos conceitos e ferramentas fornecidos nos treinamentos de capacitações ainda não estão totalmente implantados e colocados em prática pelos planos de trabalho de longo prazo.

Analisando os indicadores que serviram como aferidores do resultado de método, observou-se aumento de $2,7 \%$ do faturamento bruto total e de $14 \%$ no total de peças fornecidas ao longo do projeto. A aplicação do método em outras empresas 
poderá auxiliar ainda mais a cadeia como um todo, em aspectos diretamente ligados à competitividade no setor, tais como na redução de custos, agilidade na resolução de problemas, flexibilidade de processos produtivos e do fluxo de comunicação.

Apesar do sucesso inicial e limitado do projeto e dos resultados parciais positivos que foram observados, para os próximos projetos desta natureza alguns pontos deverão ser mais bem planejados, tais como a escolha das empresas fornecedoras participantes. Algumas não alinharam as atividades do projeto com seus planejamentos estratégicos de capacitações e treinamentos, pois não enviaram colaboradores a alguns dos treinamentos disponibilizados e também não deram seqüência a algumas das atividades propostas nas consultorias de intervenção e nos planos de trabalho de médio e longo prazo.

Ficou clara a necessidade de uma capacitação mais ampla em gestão estratégica, a fim de esclarecer a importância de um posicionamento de negócio bem definido em empresas de micro e pequeno porte, visto a competitividade desta cadeia de fornecimento. Também foi possível perceber a necessidade de se disponibilizar mais horas de consultoria para micro e pequenas empresas. Muitas das empresas fornecedoras que participaram do projeto não fornecem apenas para a cadeia automotiva, por esta razão não está totalmente compreendida em seus processos a exigida qualidade assegurada de produtos e procedimentos da indústria automotiva.

Desta forma, torna-se necessário agregar valor e competências à cadeia automotiva do Rio Grande do Sul e do Brasil. Políticas de capacitação dirigidas e eficazes podem ser úteis para fortalecer a indústria para os novos tempos. A criação de uma cadeia automotiva mais competitiva, expandindo a inovação, a tecnologia e a engenharia, tem o poder de elevar a cadeia à condição de eficientes geradores de inteligência industrial em geral e automotiva em particular. Uma importante etapa futura será manter a sinergia entre os participantes após a conclusão da consultoria e estender a atividade a outras empresas.

\title{
MEANS OF TRAINING OF COMPANIES PROVIDING AUTOMOTIVE CHAIN OF RIO GRANDE DO SUL
}

\begin{abstract}
The purpose of this article is to present and report a case of application of a method to empower automotive suppliers chains. The research method was the case study. The activities were part of a project of IELRS (Institute Euvaldo Lodi RS) whose goal was to increase the competitiveness of supply chains by developing and qualifying suppliers. The application involved two systemic companies of the suppliers supply chain and fifteen of these systemic suppliers with operations in Rio Grande do Sul. The method consists of short-term actions, including diagnosis and plan of work, and long-term actions, including consulting and training. The results were measured by four intermediate goals (decrease
\end{abstract}


failures, increase delivery reliability, deploy management tools, and improve quality) and two final goals (increase turnover and increase revenue). Three of intermediate goals and two finals were achieved. The main outcome of the project was to increase the quality of conformation observed in deliveries from suppliers.

Keywords: Training of suppliers, supply chain management, automotive suppliers, industrial supply.

\section{REFERÊNCIAS}

ANDRADE, C.; FURTADO, J. Discutindo processos de outsourcing da manufatura: uma análise a partir de elementos das indústrias eletrônica, farmacêutica e automobilística. In: ENEGEP, 25., 2005, Porto Alegre. Anais... Porto Alegre: ABEPRO, 2005.

ASSOCIAÇÃO NACIONAL DE FABRICANTES DE VEÍCULOS AUTOMOTORES. Carta da Anfavea. ANFAVEA, N.296, 2011a. Disponível em: <http://www.anfavea.com.br/cartas/ Carta296.pdf>. Acesso em: 10 set. 2011.

Anuário da Indústria Automobilística Brasileira. ANFAVEA, 2011b. Disponível em:< http://www.anfavea.com.br/anuario.html>. Acesso em: 10 set. 2011.

ARRIGONE, M.; ARRIGONE, A.; MUTTI, C. Automação e competitividade: um estudo de caso italiano. E-Tech: Tecnologias para Competitividade Industrial, Florianópolis, v.2, n.1, p.81-95, 2009.

BALDIN, N.; NOVAES, A.; DUTRA, N. Integração da cadeia de suprimentos na indústria automobilística. In: ENEGEP, 23., 2003, Ouro Preto. Anais... Ouro Preto: ABEPRO, 2003.

BALLOU, R. Gerenciamento da Cadeia de suprimentos/Logística empresarial. Porto Alegre: Bookman, 2006.

BORCHARDT, M. et al. Considerações sobre ecodesign: um estudo de caso na indústria eletrônica automotiva. Ambiente \& Sociedade, Campinas, v.11, n.2, p.341-353, 2008. 
BOWERSOX, D.; CLOSS, D.; COOPER, M. Gestão logística da cadeia de suprimentos. Porto Alegre: Bookman, 2006.

CHOPRA, S.; MEINDL, P. Gerenciamento da cadeia de suprimentos. São Paulo: Prentice Hall, 2003.

CHRISTOPHER, M. Logística e gerenciamento da cadeia de suprimentos. São Paulo: Thomson, 2007.

DAVIS, M.; AQUILANO, N.; CHASE, R. Fundamentos da Administração da Produção. Porto Alegre: Bookman, 2001.

DIEHL, A; VACCARO, G. Uma abordagem para implementação de qualidade assegurada no fornecimento, baseada em análise de capacidade: Um estudo de caso em uma empresa do setor automotivo. Produção Online, Florianópolis v.9, n.4, p.826-829, 2009.

FLEURY, P.; WANKE, P.; FIGUEIREDO, K. Logística e gerenciamento da cadeia de suprimentos: planejamento do fluxo de produtos e dos recursos. São Paulo: Atlas, 2008. (Coleção Coppead de Administração).

FURLAN, A.; GRANDINETTI, R.; CAMUFFO, A. How do subcontractors evolve? International Journal of Operations \& Production Management, Birmingham, v.27, n.1, p.69-89, 2007.

GUARNIERI, P; HATAKEYAMA, K. Supply Chain Management na indústria automobilística. Gestão Industrial, Ponta Grossa, v.1, n.4, p.60-68, 2005.

HARO, D.; CATEN, C. Sistemas de qualidade na indústria automobilística: uma visão geral das normas existentes e as que estão por vir. In: CONGRESSO BRASILEIRO DE ENGENHARIA DE FABRICAÇÃO, 2., 2003, Uberlândia. Anais... Uberlândia: COBEF, 2003.

JOHNSON, D. Empirical study of second-tier automotive suppliers achieving QS-9000 Reference No 718. International Journal of Operations \& Production Management, Birmingham, v.22, n.8, p.902-928, 2002.

KRAUSE, D.; SCANELL, T.; CALANTONE, R. A structural analysis of the effectiveness of buying firms' strategies to improve supplier performance. Decision Sciences, New York, v.31, n.1, p.33-55, 2000. 
KRAUSE, D.; PAGELL, M.; CURKOVIC, S. Toward a measure of competitive priorities for purchasing. Journal of Operations Management, New York, v.19, n.4, p.497-512, 2001.

KUCHENBECKER, N. O processo de terceirização e de qualificação de fornecedores. 2006. 184 p. Tese (Doutorado em Engenharia de Produção)-Universidade Federal de Santa Catarina, Florianópolis, 2006.

LIMA, M.; ZAWISLAK, P. Cadeia automotiva do Rio Grande do Sul: considerações sob a ótica da produção enxuta. In: ENEGEP, 21., 2001, Salvador. Anais... Salvador: ABEPRO, 2001.

MESQUITA, L.; LAZZARINI, S.; CRONIN, P. Determinants of firm competitiveness in Latin American emerging economies: evidence from Brazil's auto-parts industry. International Journal of Operations \& Production Management, Birmingham,v.27, n.5, p.501-523, 2008.

PIRES, S. Gestão da cadeia de suprimentos: conceitos, estratégias, práticas e casos. São Paulo: Atlas, 2004.

PEREIRA, C.; FRAZÃO, L. Capacitação de fornecedores: O programa fit for global approach, da empresa Robert Bosch. Gestão \& Regionalidade, São Bernardo do Campo,v.25, n.74, p.48-60, 2009.

SCAVARDA, L. et al. Trends in the world's automotive industry chain: effects in emerging countries. In: ENEGEP, 21., 2001, Salvador. Anais... Salvador: ABEPRO, 2001.

SCAVARDA, L.; HAMACHER, S.; Evolução da Cadeia de Suprimentos da Indústria Automobilística no Brasil. Revista de Administração Contemporânea, Curitiba, v.5, n.2, p.201-219, 2001. 


\section{SOBRE OS AUTORES}

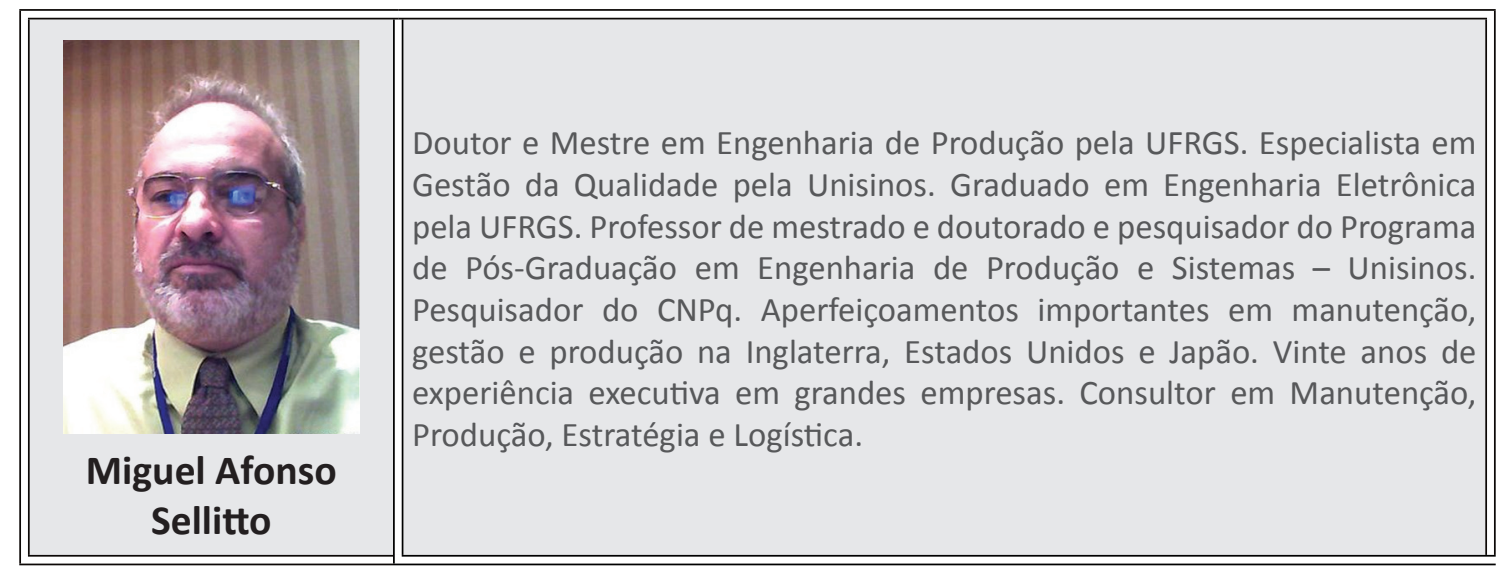

Engenheiro de Produção Mecânica, graduado pela Unisinos. Consultor
em engenharia de produção, especializado na indústria automotiva.
Seus principais campos de conhecimento são: gerência de produção,
estratégia, qualidade, e logística Atua principalmente em atividades de
educação, treinamento, desenvolvimento, consultoria e execução de
ações de campo associadas á indústria automotiva. Possui experiência em
ações de desenvolvimento setorial, principalmente ligadas à promoção da
competitividade, estratégia e gestão da qualidade na indústria.

Deseja-se reconhecer a importância das empresas e dos gestores que aceitaram participar da pesquisa. Parte deste trabalho foi financiada pelo CNPq.

Originais recebidos em: 19/04/2013

Texto aprovado em: 15/10/2013 